Modelo regulatório da liberação comercial de plantas geneticamente modificadas no Brasil: existe um consenso? Denise Gallo Pizella, Marcelo Pereira de Souza, Moacyr Lobo da Costa Jr.

\title{
MODELO REGULATÓRIO DA LIBERAÇÃO COMERCIAL DE PLANTAS GENETICAMENTE MODIFICADAS NO BRASIL: EXISTE UM CONSENSO?
}

\author{
Regulatory model of the commercial release of genetically modified crops in Brazil: \\ is there a consensus?
}

\author{
Denise Gallo Pizella \\ Universidade Estadual Paulista, Ilha Solteira, São Paulo, Brasil \\ denise@bio.feis.unesp.br \\ Marcelo Pereira de Souza \\ Universidade de São Paulo, Ribeirão Preto, São Paulo, Brasil \\ mps@usp.br \\ Moacyr Lobo da Costa Jr. \\ Universidade de São Paulo, Ribeirão Preto, São Paulo, Brasil \\ mlobojr@eerp.usp.br
}

Artigo recebido em 12/11/2013 e aceito para publicação em 11/06/2014

RESUMO: A liberação comercial agrícola de plantas geneticamente modificadas (PGMs) é uma questão que suscita discussões e controvérsias entre os diferentes setores da sociedade civil e especialistas da área ambiental em relação ao seu plantio em escala comercial, dados os potenciais impactos socioambientais e econômicos que podem suscitar ao longo do tempo. O presente trabalho analisa a questão por meio de questionários aplicados junto aos diversos atores sociais envolvidos de forma direta ou indireta com o assunto, visando detectar as visões existentes sobre a liberação comercial de PGMs no Brasil. Os resultados apontam a diversidade de opiniões entre os agentes entrevistados, mas que convergem para uma necessidade comum de revisão do modelo regulatório de PGMs brasileiro no que se refere aos aspectos institucionais e os instrumentos ambientais utilizados para sua avaliação prévia antes da liberação comercial.

Palavras-chave: Plantas geneticamente modificadas (PGMs); Análise de Risco; Estudo de Impacto Ambiental.

ABSTRACT: The commercial release of genetically modified crops (GM crops) is an issue of discussion and controversy among different sectors of civil society and experts in the environmental area in relation to its cultivation on a commercial scale, given the potential social, environmental and economic impacts that may ensue over time. This paper examines the issue through questionnaires together with the various actors involved directly or indirectly to the subject, to detect the existing views on the commercial release of GM crops in Brazil. The results show the diversity of opinion among the agents interviewed, but converge to a common need for revision of the Brazilian regulatory model of GM crops with regard to its institutional aspects and the environmental tools used for evaluation prior the commercial release.

Keywords: Genetically modified crops (GM crops); Risk Analysis; Project EIA.

DOI: http://dx.doi.org/10.1590/1982-451320140312 


\section{INTRODUÇÃO}

O plantio comercial de Plantas Geneticamente Modificadas (PGMs) apresenta um crescimento acentuado em todo o mundo desde sua liberação comercial nos EUA no início da década de 1990, com predominância de variedades tolerantes a herbicidas e com propriedades inseticidas (BROOKES; BARFOOT, 2005). A despeito deste crescimento, a liberação para o plantio comercial de PGMs apresenta controvérsias em termos mundiais, em função das incertezas quanto aos impactos potenciais sobre a saúde humana, aos demais animais e vegetais, ao meio ambiente e à economia (STIRLING, 2000; VEIGA, 2007; ROBIN, 2008; SMITH, 2009). No Brasil, do mesmo modo, o assunto é bastante polêmico, dividindo opiniões em todos os setores sociais (VEIGA, 2007; GUIVANT, 2006). Tal questão assume relevância dada à segunda posição ocupada pelo país no ranking mundial dos produtores de plantas transgênicas (ISAAA, 2009) ao mesmo tempo em que se situa como o maior detentor de diversidade biológica do mundo.

Segundo Silveira e Buainain (2007), a polêmica em torno do plantio de organismos geneticamente modificados não retrata apenas o debate ideológico em torno do tema, mas uma real controvérsia científica, sem uma solução até o presente. Há uma indefinição dos riscos socioambientais de sua liberação e comercialização, já que a teoria de análise de riscos pressupõe a existência de perigos que sejam mais ou menos perceptíveis, fato este que contribui para as discórdias acerca de sua liberação no meio ambiente. Daí a aplicabilidade do Princípio da Precaução nestas situações, como estabelecido pelo Protocolo de Cartagena sobre Biossegurança de 2000.

No caso dos organismos geneticamente modificados em geral, Veiga (2007) aponta para a existência de uma probabilidade subjetiva, que se relaciona mais à incerteza das consequencias ao meio do que da possibilidade de se prever perigos com certo nível de exatidão. Diferentemente da idéia de um perigo possível de ser analisado, porque de certa forma já definido, a incerteza "define a possibilidade de ocorrer um fato - em geral perigoso - sem que seja possível ter a noção sequer aproximada da probabilidade de sua ocorrência. Deste modo, alguns autores (HINDMAR-
SH, 1990; STIRLING, 2000; WHALES; MYTHEN, 2002; ELY, 2002; PELAEZ, 2004; HENRY, 2006; SUZUKI, 2006 e MYSZCZUK et al., 2009) levantam dúvidas a respeito da utilização do instrumento Análise de Risco - comumente utilizado para a avaliação prévia das PGMs - como adequado para avaliar as implicações socioambientais que decorrem de sua liberação ambiental e posterior comercialização.

Em relação aos atores sociais e os posicionamentos que se dão em torno do uso de transgênicos, podem-se identificar, em geral, três ideias predominantes, quais sejam: defesa da liberação e uso de OGMs sem restrições, contrária à sua liberação frente à ausência de conhecimentos científicos suficientes e uma terceira, favorável ao uso com ressalvas (ALTIERI; NICHOLLS, 2000; DALE, CLARLKE; FONTES, 2003; SILVEIRA; BUAINAIN, 2007; PESSÔA, 2007; ROBIN, 2008). No entanto, apesar das diversas premissas e proposições identificadas no debate nacional e internacional sobre esta questão, não é possível simplificar o posicionamento dos diversos atores sociais envolvidos, já que muitos adotam uma miscelânea das opiniões acima apresentadas, dependendo de seu grau de informação, da formação acadêmica ou sua ausência, das experiências adquiridas e do sistema de valores e interesses envolvidos.

A regulação de PGMs no Brasil ancora-se na Lei de Biossegurança - Lei no 11.105/2005 - , que estabeleceu a Comissão Técnica Nacional de Biossegurança (CTNBio) como órgão deliberativo sobre as pesquisas e liberações de plantios comerciais de PGMs, além de ter a prerrogativa de decidir sobre a necessidade de realização de estudos de impactos ambientais para embasar as tomadas de decisão. Já os Ministérios da Saúde, Meio Ambiente e Agropecuária e Abastecimento são os órgãos responsáveis pelo registro e fiscalização destes organismos (BRASIL, 2005). Por conseguinte, um conflito de normas foi posto, na medida em que as leis específicas da área ambiental atribuíram aos órgãos pertencentes ao Sistema Nacional do Meio Ambiente (SISNAMA) a gestão sobre o meio ambiente, incluindo o licenciamento de atividades relacionadas ao uso de PGMs, para o qual se faz necessária a elaboração de Estudos de Impactos Ambientais (EIAs) (BRASIL, 1997), o que não é observado na prática (MILARÉ, 2005; MACHADO, 2013). 
Apesar da existência de conflitos de interesses e da polêmica sobre o assunto, existem poucos estudos no país que visam identificar as visões dos diversos agentes interessados (GUIVANT, 2006). As pesquisas até então foram efetuadas por empresas e em trabalhos acadêmicos e se restringiram basicamente aos riscos e benefícios da aplicação da biotecnologia no setor agrícola, podendo-se observar a ausência de abordagens que considerassem os aspectos relacionados à maneira como os transgênicos são regulados no país, dentre os quais se podem citar: a permeabilidade social nas tomadas de decisão, a disponibilidade de informações sistematizadas, os instrumentos de avaliação de impactos ambientais utilizados e sua adequação ao objeto de estudo, a consideração de outras ações estratégicas nos processos deliberativos e o monitoramento pós-comercial das variedades liberadas.

$O$ presente artigo faz parte de uma pesquisa acadêmica realizada pelo Núcleo de Estudo em Política Ambiental do Programa de Pós-Graduação em Ciências da Engenharia Ambiental do Centro de Recursos Hídricos e Ecologia Aplicada da EESC-USP que buscou analisar o(s) instrumento(s) de avaliação ambiental mais adequado(s) para a liberação comercial de plantas geneticamente modificadas, além de avaliar seu modelo regulatório, identificando a percepção de alguns setores sociais interessados sobre este tema e, a partir das constatações feitas, propor encaminhamentos.

\section{METODOLOGIA}

Para a consecução dos objetivos propostos, aplicou-se um questionário abrangendo aspectos relacionados à liberação comercial de plantio de PGMs no país, que contemplou: participação da sociedade nos processos deliberativos; instituições governamentais que devem/deveriam ter prerrogativas sobre este assunto; acesso às informações como, por exemplo, os documentos submetidos pelas empresas proponentes à CTNBio, os relatórios produzidos pelos órgãos fiscalizadores e a rotulagem dos produtos que contém material transgênico (as quais estariam presentes no Sistema de Informações sobre Biossegurança, caso fosse implementado) e os instrumentos ambientais mais adequados para subsidiar as tomadas de decisão sobre a liberação comercial de PGMs, quais sejam, a Análise de Risco (AR) e os Estudos de Impacto Ambiental (EIA). Além disto, questionou-se o grau de importância dado a alguns aspectos a serem considerados em estudos ambientais, como a consideração de impactos ambientais cumulativos e de ações estratégicas relacionadas com o objeto de análise e monitoramento pós-comercial.

O questionário apresentou perguntas que foram enviadas a 140 potenciais participantes, abrangendo técnicos, pesquisadores ou atuantes em diversos setores, cuja seleção se baseou na atuação em áreas que fazem interface direta ou indireta com o assunto em questão, sendo aplicadas por meio de correio eletrônico, método adotado pela facilidade de comunicação com os atores selecionados, dadas as distâncias físicas existentes entre as partes envolvidas. Os agentes sociais foram agrupados por categorias de atuação profissional relacionada aos diversos aspectos do tema "transgênicos", a saber: (1) Biossegurança e / ou Biotecnologia - pesquisadores que atuam no desenvolvimento de plantas geneticamente modificadas e/ou na biossegurança ambiental e de saúde humana e animal; (2) Direito e Regulamentação - profissionais do Direito especializados na área ambiental e/ou atuantes em órgãos de proteção dos direitos difusos; (3) Ecologia - pesquisadores da área de ecologia com amplo conhecimento do tema; (4) Meio Ambiente pesquisadores da área de ciências ambientais, incluindo os instrumentos da política ambiental brasileira; e (5) Organização Não-Governamental de atuação ambientalista ou social - ONG - organizações de ampla visibilidade nacional com relação ao tema, dotadas de diversos posicionamentos a respeito da liberação comercial de PGMs.

$\mathrm{O}$ anonimato dos participantes foi preservado com a intenção de garantir a segurança e a ausência de constrangimentos aos participantes, os quais foram identificados com algarismos arábicos e denominados de "Respondentes", quando da citação das opiniões mais relevantes.

Realizou-se uma análise estatística simples para o conjunto de respostas obtidas de todas as categorias ou setores sociais participantes, a qual foi representada na forma de figuras para posterior análise. Uma comparação entre as respostas dadas por cada 
Modelo regulatório da liberação comercial de plantas geneticamente modificadas no Brasil: existe um consenso? Denise Gallo Pizella, Marcelo Pereira de Souza, Moacyr Lobo da Costa Jr.

categoria em separado também foi feita. No entanto, optou-se por não mostrar as figuras que demonstram as opiniões das categorias em separado, mas sim em seu conjunto, por uma questão do espaço disponível para as discussões.

\section{RESULTADOS E DISCUSSÃO}

Dentre os 140 formulários enviados, obteve-se um retorno de 37 respostas, representando $26 \%$ da totalidade de questionários enviados, apesar da persistência dos autores em enviá-los repetidas vezes. Neste sentido, não é possível realizar inferências sobre a ausência de um grande número de respostas. Por meio da Tabela 01, observa-se o percentual de respostas para cada categoria de participantes:

Tabela 1. Percentual de respostas em função dos questionários enviados, por categorias.

\begin{tabular}{lllll} 
Categorias & Agentes Sociais & $\begin{array}{l}\text { Questionários } \\
\text { enviados }\end{array}$ & $\begin{array}{l}\text { Questionários } \\
\text { respondidos }\end{array}$ & $\begin{array}{l}\text { Porcentagem de } \\
\text { respostas }\end{array}$ \\
\hline 01 & $\begin{array}{l}\text { Biossegurança e/ou biotecno- } \\
\text { logia }\end{array}$ & 47 & 6 & $13 \%$ \\
\hline 02 & Direito e Regulamentação & 18 & 4 & $22 \%$ \\
\hline 03 & Ecologia & 18 & 7 & $39 \%$ \\
\hline 04 & Meio Ambiente & 35 & 12 & $34 \%$ \\
\hline 05 & $\begin{array}{l}\text { Organização Não-Governa- } \\
\text { mental }\end{array}$ & 22 & 8 & $36 \%$ \\
\hline TOTAL & & 140 & 37 & $26 \%$ \\
\hline
\end{tabular}

Fonte: Pesquisa direta. Org. dos autores.

Conforme a Tabela 1 observa-se que existe uma discrepância - para menos - no porcentual de respostas, que é dada pela categoria 1 - biossegurança e/ou biotecnologia, com apenas $13 \%$ de retorno, cuja razão não pode ser justificada.

Em seguida, serão apresentadas as análises estatísticas e qualitativas de cada uma das questões realizadas.

\section{Participantes para as tomadas de decisão}

Neste item, serão apresentadas e discutidas as visões dos participantes quanto aos setores sociais que devem participar nas tomadas de decisão sobre a liberação de PGMs assim como as instituições que devem ou deveriam atuar nos processos deliberativos sobre as mesmas.
Indagou-se, inicialmente, a respeito dos agentes sociais que devem ou deveriam participar nas tomadas de decisão sobre PGMs, para além das autoridades competentes. Neste ínterim, foi apresentada uma lista com potenciais participantes, relacionados diretamente ao assunto em questão, a saber: especialistas na área de biotecnologia, biossegurança, ecologia, meio ambiente, saúde, produtores agrícolas, consumidores e Organizações não governamentais de cunho socioambientalista. Além disto, outras áreas poderiam ser citadas espontaneamente. O entrevistado poderia escolher mais de uma alternativa. As respostas estão representadas na Figura 1. 
Figura 1. Agentes sociais que devem participar das decisões sobre a liberação de PGMs.

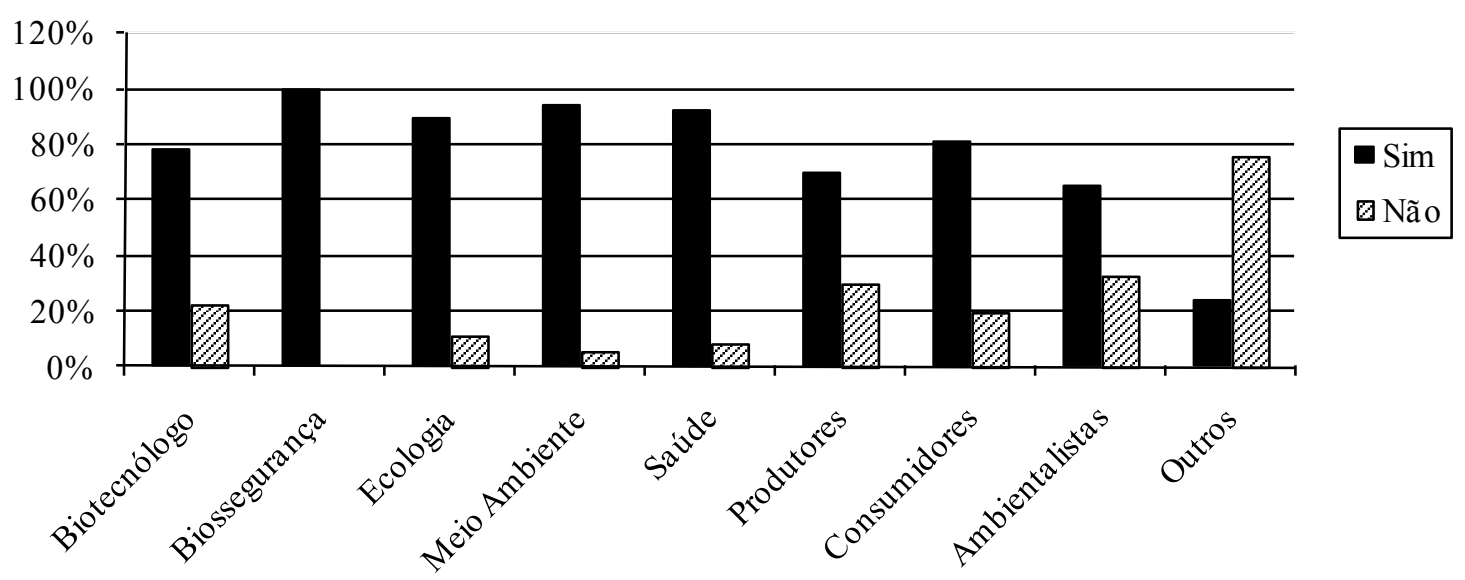

Fonte: Pesquisa direta. Org. dos autores.

A figura 1 mostra que o conjunto dos entrevistados apontou para números de participação acima de $60 \%$ a todos os agentes sociais indicados, evidenciando que é desejável uma participação plural no processo decisório.

De modo geral, todos os setores obtiveram uma representação aproximada nas respostas, com exceção de "produtores" e "ambientalistas", cujos valores apresentaram-se mais baixos. A participação de especialistas em biossegurança, por sua vez, é considerada importante de forma unânime.

Quanto às categorias em específico, destacam-se dois comentários de conteúdo diverso feitos por participantes da categoria 01 (Biossegurança e/ou Biotecnologia), entre um que atua na área de biossegurança e que acha importante a participação de "pequenos e grandes [produtores] da agricultura familiar e orgânica" (Respondente 05) enquanto que o respondente 03 (biotecnólogo) opinou da seguinte forma:

Todos devem participar discutindo o assunto, mas os aspectos técnicos devem prevalecer. Não podemos deixar questões ideológicas e opiniões baseadas no "achismo" predominarem. É necessário ter uma discussão e uma decisão utilizando dados científicos, econômicos, sociais e ambientais.

Já a maioria dos respondentes da categoria 05 (ONG), cujos diversos membros pertencem às associações ambientalistas, considerou a participação dos biotecnólogos como importante. A categoria 02 (Direito e Regulamentação) é a mais favorável quanto a uma maior participação dos agentes sociais interessados no processo decisório, seguidos das categorias 04 (Meio Ambiente) e 03 (Ecologia).

Além dos agentes sociais indicados, alguns ecólogos sugeriram outros, tais como: membros relacionados à indústria de alimentos, da área de comunicação social e de mercado. Já os respondentes da área de Meio Ambiente sugeriram especialistas nas áreas de economia e sociologia rural e da área jurídica.

No tocante às ONGs, outros agentes sociais foram levantados, tais como: especialistas em antropologia, psicologia, sociologia; comunidades tradicionais (como quilombolas e índios), ONGs e laboratórios que testam organismos geneticamente modificados (OGMs).

Os participantes foram também questionados sobre as instituições que deveriam ter o poder decisório final a respeito da liberação comercial (em larga escala) de PGMs. Deste modo, foram relacionadas as seguintes instituições (sendo que mais de uma alternativa poderia ser escolhida): Comissão Técnica Nacional de Biossegurança (CTNBio), Conselho Nacional de Biossegurança (CNBS), Ministério do Meio Ambiente (MMA), Ministério da Agricultura, Pecuária e Abastecimento (MAPA), Ministério da Ciência e Tecnologia (MCT) e o Ministério da Saúde (MS), uma avaliação conjunta de todos eles ("Todos") e outras ("Outra"). Vale ressaltar que as instituições 
Modelo regulatório da liberação comercial de plantas geneticamente modificadas no Brasil: existe um consenso? Denise Gallo Pizella, Marcelo Pereira de Souza, Moacyr Lobo da Costa Jr.

escolhidas para o questionário fazem parte do processo regulatório de PGMs no Brasil, sendo que a tomada de decisão a respeito da liberação ou não das mesmas cabe à CTNBio, de acordo com o modelo vigente.

As respostas estão apresentadas na Figura 2, a seguir

Figura 2. Instituições que devem/deveriam participar da tomada de decisões sobre a liberação de PGMs.

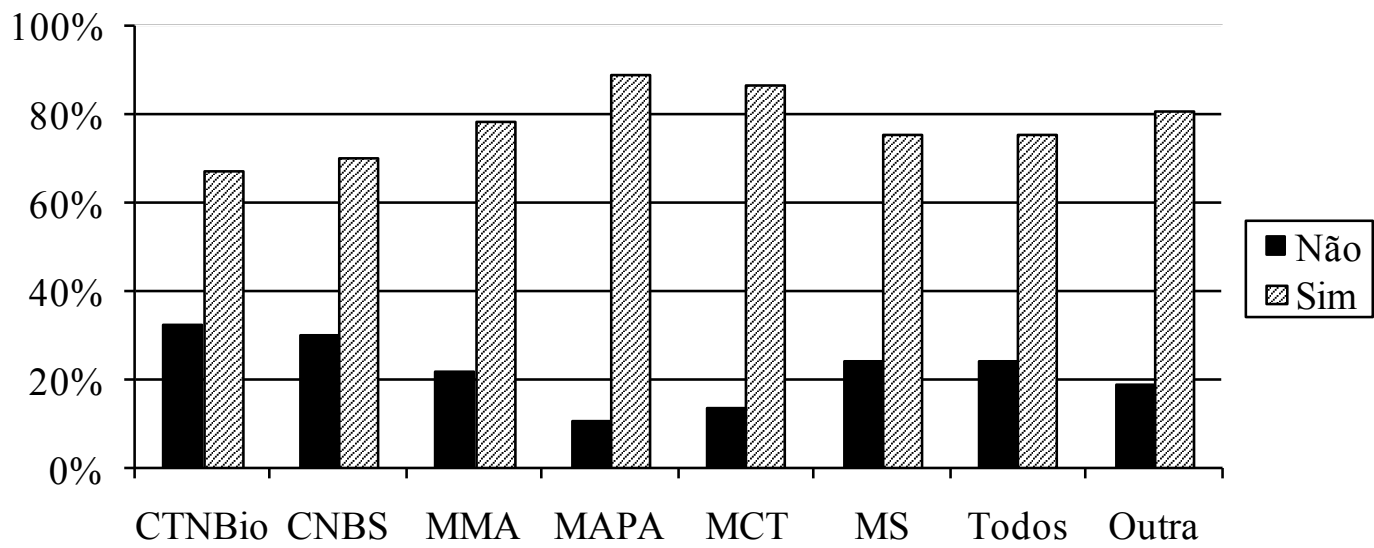

Fonte: Pesquisa direta. Org. dos autores.

As respostas obtidas apontam que todas as instituições elencadas devem participar do processo decisório com mais de $60 \%$ de indicação, sendo a maior parte com mais de $70 \%$ e alguns com mais de $80 \%$, com predominância do MMA, MAPA e MCT, coincidindo com o porcentual obtido na resposta "todos", ou seja, que todos devem participar, indicando que na opinião dos participantes, todas as instituições elencadas devem participar do processo decisório. Um fato curioso a ser destacado nesta questão é a porcentagem relativamente baixa alcançada pelo MMA, órgão que abrange o IBAMA e demais instituições governamentais que, por lei, têm a incumbência de decidir sobre o licenciamento das atividades potencialmente poluidoras, dentre as quais se encontra a liberação ambiental de OGMs (caso a CTNBio defina a liberação do transgênico em análise como um empreendimento potencialmente poluente ao meio ambiente e à saúde humana). No entanto, dada a não manifestação por escrito dos que desconsideraram a importância da atuação do MMA, torna-se difícil inferir a respeito de suas razões para tanto.

Em relação às categorias, a categoria 01 (Biotecnologia e Biossegurança) foi a mais refratária à atuação da grande maioria dos órgãos governa- mentais apontados, considerando apenas a CTNBio como instância decisória superior e, curiosamente, demonstrou-se contrária à atuação do Ministério da Ciência e Tecnologia, do qual a CTNBio faz parte. Na categoria 02 (Direito e Regulamentação), metade dos respondentes foi favorável à uma maior coordenação institucional, sendo que apenas um dos respondentes, atuante na área de Regulamentação, é favorável à participação exclusiva da CTNBio e CNBS.

Os ecólogos foram favoráveis, em sua maioria, a uma atuação conjunta de todos os órgãos apresentados.

A maioria dos representantes da categoria 04 (Meio Ambiente) optou pela CTNBio como instância superior na tomada de decisão final. Algumas proposições foram feitas, levantando-se em conta a necessidade de participação também da sociedade civil, dentre as quais se podem citar: "Um fórum ampliado, representativo da sociedade, avaliando e decidindo a partir de informações técnicas e políticas" (Respondente 21); “Todas e representantes da sociedade e da saúde" (Respondente 22) e "Poderia ser a CTNBio, mas precisaria modificar a sua composição, para que a diversidade de setores e posições da sociedade estivessem ali representados" (Respondente 25). Já a maioria dos membros de ONGs optou 
pela participação de todos os órgãos governamentais citados, também com algumas proposições principalmente em torno da atuação da sociedade civil, quais sejam: "Acho que o estado deveria fazer um amplo debate com a sociedade sobre o que são? Qual o objetivo e que benefícios trazem as Plantas GM?" (Respondente 32).

\section{Aspectos relevantes a serem considerados em estudos ambientais de PGMs.}

Com o intuito de obter a opinião dos participantes sobre a relevância de alguns aspectos socioambientais apontados em possíveis avaliações de impactos ambientais de PGMs, a questão formulada indagou sobre qual a importância de se considerar: impactos cumulativos (quando se consideram diversas variedades de PGMs cultivadas ao longo do tempo em um mesmo espaço geográfico), a opinião dos atores sociais interessados e afetados pelas liberações, as alternativas tecnológicas existentes (como cultivares orgânicas e convencionais), outras Políticas, Planos e
Programas (PPPs) relacionados no território de plantio da PGM, possíveis alternativas locacionais ao empreendimento e a existência de planos de monitoramento pós-comercial.

O intuito desta questão foi analisar se os respondentes observavam a liberação em larga escala de PGMs como um empreendimento isolado, sem conseqüências socioambientais cumulativas em longo prazo (como resistência a pragas, por exemplo) ou se a contextualizavam como um modelo de produção agrícola com características estratégicas para a economia, o meio ambiente, a segurança alimentar e a saúde da população. Daí o questionamento a respeito de se considerar outras Políticas, Planos e Programas relacionados à liberação e comercialização das PGMs e seus derivados, assim como as alternativas tecnológicas a que estes organismos se propõem a combater, tais como o controle biológico de pragas e mesmo a agricultura orgânica, dentre outras.

As respostas encontradas são ilustradas na Figura 3:

Figura 3. Na Avaliação de Impactos Ambientais de PGMs, qual a importância dos aspectos socioambientais acima abordados.

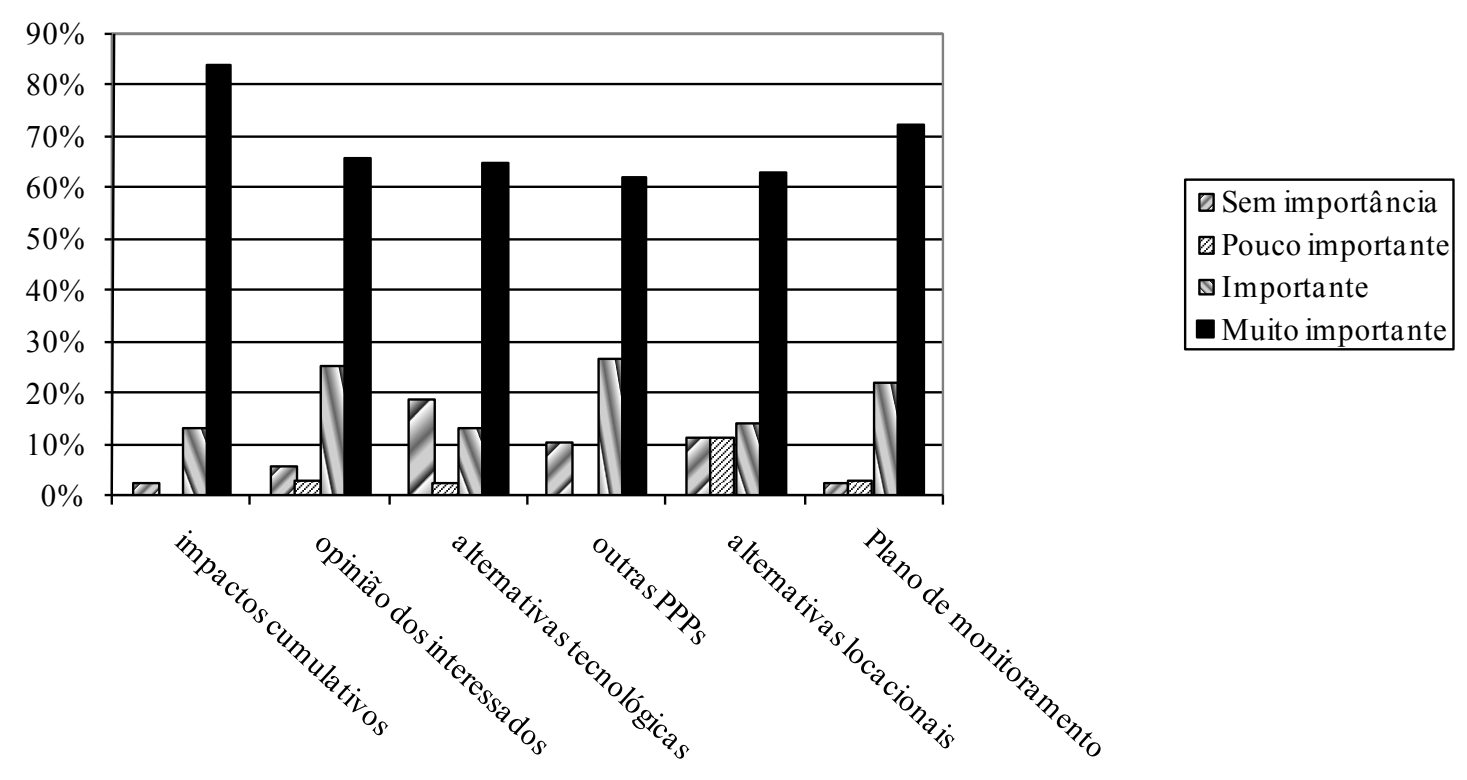

Fonte: Pesquisa direta. Org. dos autores. 
A maioria das respostas - mais de $60 \%$ - indica que os entrevistados consideram muito importante os tópicos relacionados, sendo os critérios melhor pontuados a "avaliação dos impactos cumulativos" e o "Plano de Monitoramento".

Em relação aos grupos analisados, os especialistas em biotecnologia e/ou biossegurança consideraram importantes a avaliação dos impactos cumulativos, as ações estratégicas existentes ou previstas para a área de liberação (ou seja, Políticas, Planos e Programas) e o Plano de monitoramento nos processos de avaliação para a liberação de PGMs, enquanto que a existência de alternativas tecnológicas obteve a maior porcentagem de irrelevância.

As demais categorias apresentaram respostas unânimes em considerar todos os critérios apontados como sendo "importantes" ou "muito importantes".

\section{MELHORES INSTRUMENTOS A SEREM EM- PREGADOS COMO ESTUDOS AMBIENTAIS DE PGMS: EIA OU ANÁLISE DE RISCO?}

Os participantes foram questionados sobre a potencialidade dos Estudos de Impacto Ambiental em considerar os aspectos "impactos cumulativos", "alternativas tecnológicas e locacionais", "consideração de Políticas, Planos e Programas (PPPs) relacionados à liberação comercial de PGMs", "monitoramento pós-comercial" e "participação social", como instrumento ambiental a subsidiar as tomadas de decisão sobre a liberação de PGMs, a fim de obter uma idéia a respeito do melhor instrumento para a análise prévia dos organismos em questão. Neste sentido, cabe ressaltar que, na Análise de Risco, nenhum dos aspectos acima são considerados em seu bojo, diferentemente do EIA e de outro instrumento de Avaliação de Impactos Ambientais ainda não regulamentado no Brasil: a Avaliação Ambiental Estratégica.

As respostas obtidas estão apresentadas na Figura 4:

Figura 4. Potencialidades do Estudo de Impacto Ambiental (EIA) e seu respectivo Relatório de Impacto Ambiental (RIMA) em considerar os aspectos acima abordados em uma Avaliação de Impactos Ambientais de PGMs.

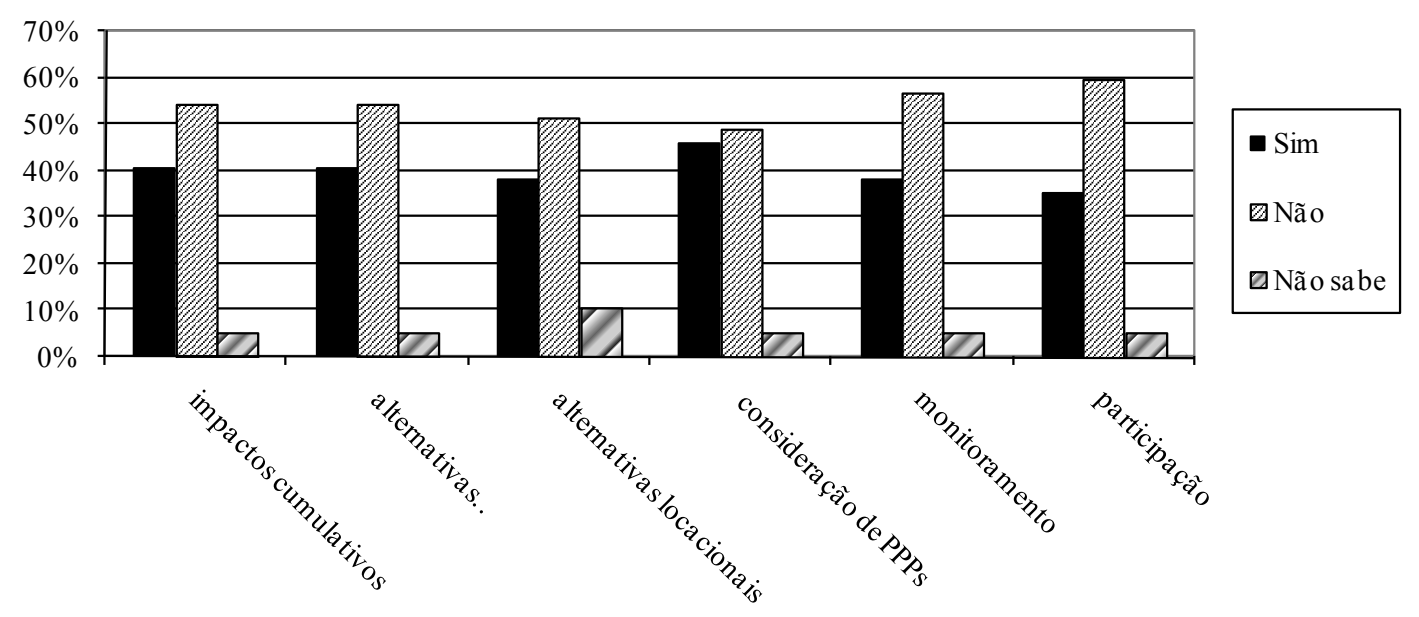

Fonte: Pesquisa direta. Org. dos autores. 
De acordo com a figura 4 , mais de $50 \%$ dos participantes entende a inadequação do instrumento EIA/RIMA para o cumprimento de todos os critérios apresentados.

A Resolução CONAMA 01/86 determina que os impactos cumulativos devem constar na avaliação das atividades sujeitas ao EIA, assim como as alternativas (tanto locacionais e tecnológicas) e outras PPPs (BRASIL, 1986). Além disto, o monitoramento da atividade ao longo de seu ciclo de vida deve ser contemplado até o momento de desativação do projeto, e a participação social é garantida por meio das audiências públicas (BRASIL, 1997).

No entanto, o instrumento EIA é utilizado para a avaliação de atividades pontuais (PARTIDÁRIO, 2002; THERIVEL et al., 1994; SCHMIDT; JOÃO; ALBRECHT, 2005; ALSHUWAIKHAT, 2005), que não pertencem ao caso em questão de liberação em larga escala de PGMs, a qual é realizada para o território nacional como um todo. Apesar de não apresentarem justificativas para suas respostas, podemos inferir que os participantes externalizaram o descontentamento com o acúmulo de experiências em EIAs realizados no país quanto ao cumprimento dos aspectos abordados. O EIA foi considerado ineficiente especialmente em relação ao monitoramento e à participação social, o que pode ser atribuído pelo fato de o monitoramento da atividade se extinguir com sua finalização, impedindo a deteç̧ão de impactos ambientais, sociais e econômicos de longo prazo e por uma percepção dos respondentes da baixa permeabilidade social nas tomadas de decisão quando do licenciamento de atividades, que se dá apenas por meio de audiências públicas, quando muito.

Pode-se constatar, porém, algumas divergências de respostas, já que alguns participantes opinaram de forma favorável ao uso do EIA para atingir os critérios levantados.

Na categoria 01 (Biotecnologia e/ou Biossegurança), a maioria considerou o EIA inapropriado a todos os aspectos, talvez em função da difusão da Análise de Risco como mais adequada, especialmente entre os biotecnólogos, principais defensores e atuantes no uso deste instrumento para a avaliação de PGMs. A categoria 02 (Direito e Regulamentação) apresentou maiores divergências neste aspecto, com metade de respostas favoráveis ao EIA nos aspectos "impactos cumulativos", "alternativas locacionais" e "consideração de outras PPPs". Quanto ao monitoramento e alternativas tecnológicas, todos consideraram o EIA inadequado.

Os membros da área de Ecologia apontaram o EIA como um instrumento apropriado apenas para a análise de alternativas locacionais, sendo o monitoramento e a participação social considerados seus piores aspectos.

A categoria 05 (Meio Ambiente) considerou o EIA adequado ao cumprimento de todas as funções abordadas, com exceção da participação social, cujas opiniões foram mais divergentes. Pode-se inferir que tal resultado se deu em razão de uma maior atuação dos participantes desta área em EIA/RIMAs e/ou pelo descrédito ou insuficiência do uso da Análise de Risco em estudos ambientais sobre a liberação de PGMs. No entanto, ao mesmo tempo demonstraram um desconhecimento das atribuições deste instrumento para o cumprimento dos requisitos abordados, já que a função do EIA é a avaliação dos impactos ambientais de empreendimentos pontuais, o que não seria o caso da liberação em escala comercial de PGMs. $\mathrm{O}$ instrumento mais adequado para abarcar todos os requisitos levantados nesta questão é a Avaliação Ambiental Estratégica, não regulamentada no Brasil, como anteriormente mencionado.

As ONGs caracterizaram-se por apresentar maiores divergências de respostas, com metade dos participantes avaliando os critérios como adequados ou não. Apenas em relação aos impactos cumulativos e alternativas locacionais a maioria considerou o EIA como um instrumento inadequado. Pode-se inferir a maior diversidade de opiniões em função da heterogeneidade do grupo.

Da mesma maneira, as respostas questionam o potencial de aplicação dos mesmos parâmetros de avaliação de impactos ambientais pelo instrumento Análise de Risco, obtendo-se as respostas apontadas na Figura 5: 
Figura 5. Potencialidades do instrumento Análise de Risco em considerar os aspectos acima abordados em uma Avaliação de Impactos Ambientais de PGMs.

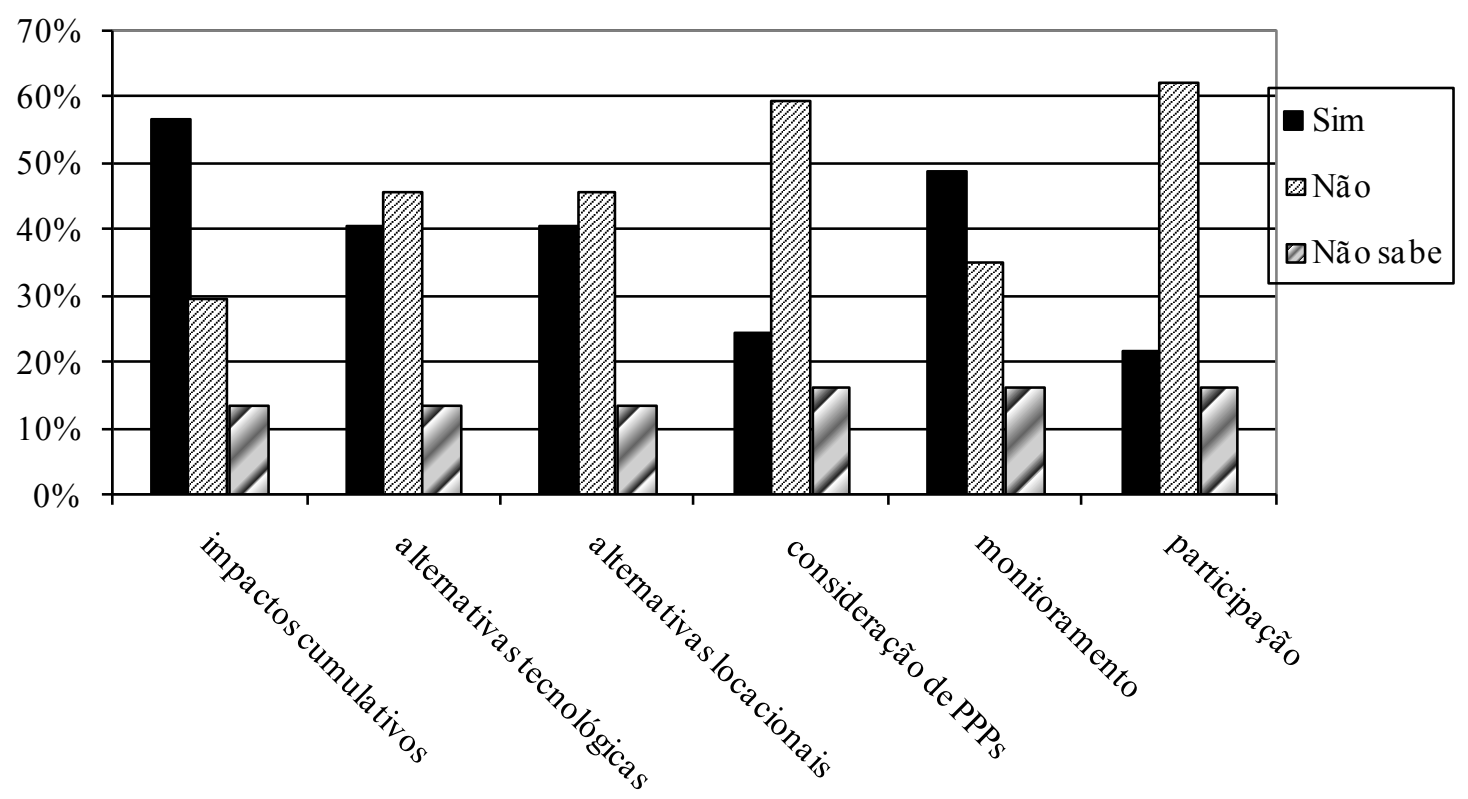

Fonte: Pesquisa direta. Org. dos autores.

Diferentemente da questão anterior, a Análise de Risco foi vista pela totalidade dos respondentes como um instrumento de avaliação que cumpre ao menos dois dos critérios abordados, quais sejam, a consideração de impactos cumulativos e o monitoramento. A relevância dos objetivos de outras PPPs durante a análise de risco é o critério considerado mais crítico pelos participantes.

De fato, a Normativa $\mathbf{n}^{\circ}$ 05/2008 da CTNBio (CTNBio, 2008) que dispõe sobre os procedimentos de Análise de Risco não contempla os aspectos "alternativas locacionais e tecnológicas", "consideração de outras PPPs" e a participação social só é permitida quando da solicitação de audiências públicas pela Comissão, como disposto na Lei de Biossegurança. No entanto, o monitoramento, apesar de exigido, deve ser realizado em até cinco anos após a finalização do plantio de PGMs, apesar de nenhuma empresa até então ter apresentado seus Planos de Monitoramento, contrariando a norma vigente.

Apesar de algumas abordagens de Análise de Risco levarem em conta os potenciais impactos cumulativos, há muitas divergências entre a comunidade científica neste sentido, pois, assim como para o EIA, o instrumento não se destina a avaliar atividades cuja amplitude se dá em larga escala, como no caso de PGMs (STIRLING, 2000; SNOW et al., 2005). Pode-se inferir a ausência de conhecimento dos respondentes quanto a estes aspectos ou que suas respostas se deram em função da utilização da Análise de Risco como única forma de avaliação de impactos de PGMs atualmente realizada no país.

A categoria 01 (Biotecnologia e Biossegurança) considerou a Análise de Risco adequada à avaliação dos impactos cumulativos e ao monitoramento, apresentando algumas divergências de opiniões quanto aos demais critérios. Pode-se inferir tal resultado pelo conhecimento de que a AR realmente não tem a atribuição de analisar os aspectos abordados, conforme a Normativa ${ }^{\circ}$ 05/2008 da CTNBio. No entanto, os impactos cumulativos não se fazem presentes nesta norma.

A categoria 02 (Direito e Regulamentação) teve a maioria de seus membros considerando o instrumento inapropriado em todos os critérios levantados. Já a categoria 03 (Ecologia) apresentou maiores divergências de opiniões, com a maioria opinando sobre a adequação da Análise de Risco quanto à avaliação dos impactos cumulativos, das alternativas (locacionais e tecnológicas) e o monitoramento. Esta área apresentou um maior número de respostas "Não sei", demonstrando o desconhecimen- 
to sobre os propósitos do instrumento.

A categoria 04 (Meio Ambiente) opinou de forma favorável ao uso da AR para a avaliação dos impactos cumulativos e a grande maioria considera o instrumento inadequado à participação social. No tocante às ONGs, a maioria dos respondentes considerou a Análise de Risco apropriada à consideração dos impactos cumulativos $\mathrm{e}$ às alternativas (tecnológicas e locacionais), com discordâncias mais significativas nos critérios "consideração de outras PPPs", "monitoramento" e "participação". Tal resultado pode ser dado em função da diversidade das organizações participantes e/ou também de um possível desconhecimento sobre o instrumento em questão.

Importante frisar que a Análise de Risco foi vista como instrumento que não contempla os demais Planos e Programas e que não propicia a participação da sociedade por mais de $60 \%$ das respostas totais.

\section{Entendimentos sobre o modelo decisório sobre libera-} ção comercial de plantio de PGMs adotado no Brasil.

Indagados a respeito do sistema regulatório de liberação comercial do plantio de PGMs no Brasil, os participantes deveriam optar pelas alternativas "insatisfatório" ou "satisfatório" (Figura 6), em relação a diversas questões presentes no mesmo. Os critérios contemplados para a avaliação na pergunta: existência de coordenação institucional no sistema regulatório de OGMs brasileiro, legitimidade e transparência nas decisões, inserção de aspectos ambientais, sociais e econômicos quando da decisão de se liberar tais organismos ambientalmente ou para a comercialização, a implementação do Sistema de Informação em Biossegurança (SIB) previsto em Lei, mas ainda inexistente, ações de fiscalização dos impactos socioambientais e econômicos decorrentes das liberações pelos órgãos responsáveis, adoção de medidas preventivas para se evitar tais impactos e análise de outras PPPs (Políticas, Planos ou Programas) correlatas nos processos decisórios, tais como o PRONAF, Planos de Manejo de Unidades de Conservação, Programas de Assentamento para Reforma Agrária, outros Planos Agrícolas não envolvendo PGMs, dentre outras.

As respostas estão expressas na Figura 6, a seguir:

Figura 6. Avaliação de alguns aspectos do marco regulatório sobre PGMs no Brasil.

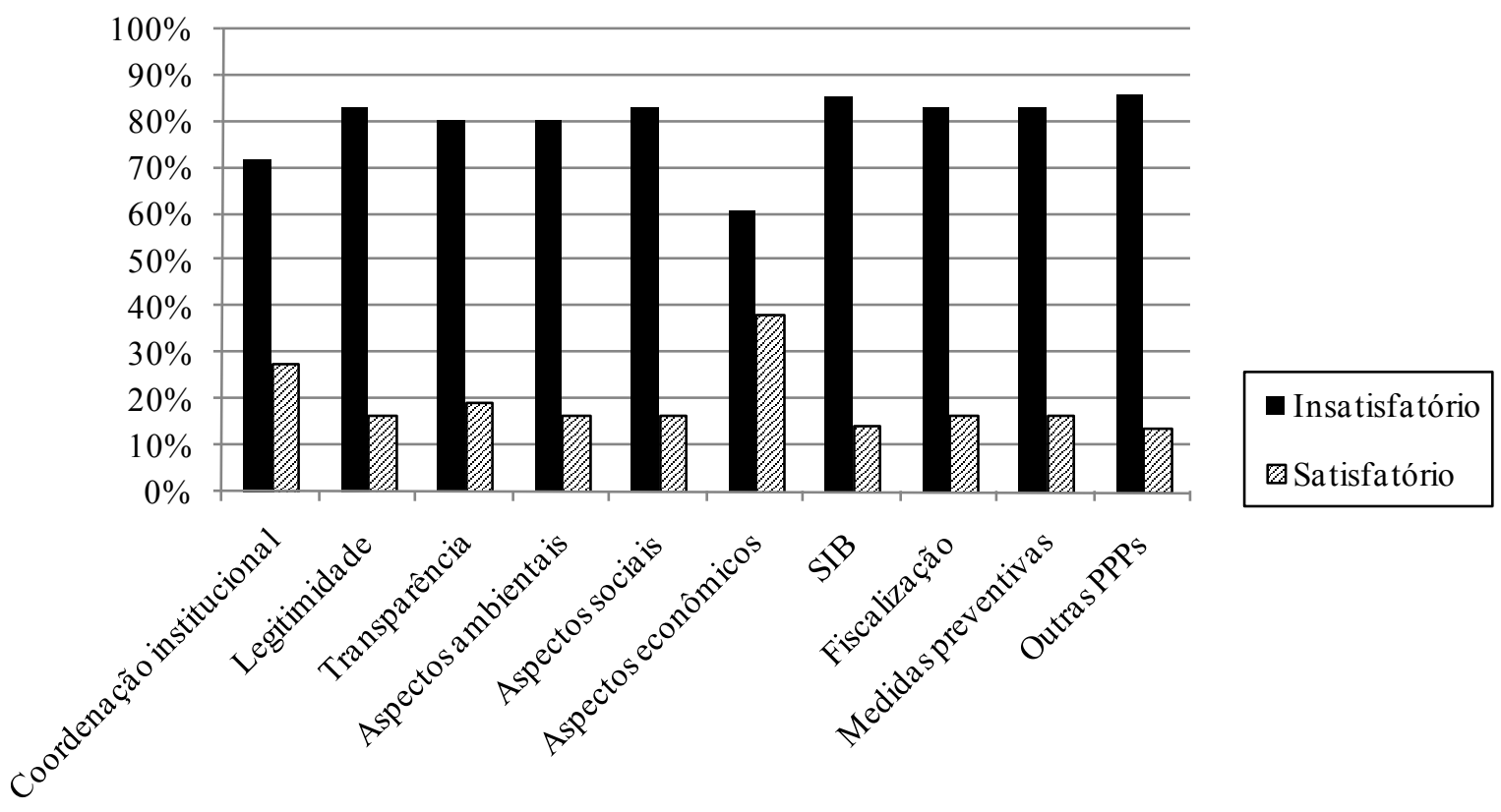

Fonte: Pesquisa direta. Org. dos autores. 
Analisando-se a figura 6, percebe-se que a maioria dos participantes - mais de $60 \%$ em todos os critérios e $80 \%$ na maioria - considerou insatisfatória a condução do processo decisório sobre a liberação de PGMs no Brasil.

Sobre as categorias especificamente, a categoria 01 (Biotecnologia e/ou Biossegurança) foi a que mais se mostrou satisfeita com o modo de condução das decisões, considerando insatisfatórios os seguintes aspectos: "legitimidade", "existência do SIB" e "consideração de outras PPPs". A categoria 02 (Direito e Regulamentação) considerou todos os aspectos como insatisfatórios, o mesmo se sucedendo com Ecologia, excetuando os "aspectos econômicos", sendo este o critério em que metade das respostas da categoria 04 (Meio Ambiente) considerou como satisfatório. Já as ONGs consideraram todos os critérios como insatisfatórios.

\section{CONCLUSÕES}

As respostas indicaram que, para a maioria dos participantes, a liberação de PGMs no país é considerada uma questão com o potencial de ocasionar impactos sociais, ambientais e econômicos positivos e negativos, interferindo sobre os objetivos ambientais e agrícolas pretendidos para o país, mas que não apresenta uma boa condução institucional. Apresentou-se a necessidade de levar em conta os potenciais impactos negativos cumulativos que se dão a partir de liberações sucessivas de PGMs em um horizonte temporal e espacial amplos; considerar as alternativas de localização e de tecnologias existentes para atender as demandas da sociedade, além da importância de se efetivar o monitoramento pós-comercial a fim de que impactos ambientais e sociais concretizados sejam identificados e mitigados, possibilitando assim um maior controle social sobre as tomadas de decisão.

Existe uma grande discrepância nos entendimentos dos diferentes setores sociais a respeito do sistema regulatório de transgênicos no Brasil. Um conflito de interesses e de entendimento muito claramente aponta para uma controvérsia sobre o tema "liberação para plantio comercial de PGMs". Também se demonstra que a maioria dos participantes se encontra insatisfeita quanto à forma de condução dos processos decisórios sobre PGMs no país, sendo que as opiniões variaram de acordo com as categorias selecionadas, com os biotecnólogos apresentando-se mais favoráveis em relação às demais áreas de atuação. Tais especialistas mostraram-se mais refratários à participação social nas tomadas de decisão, por reduzirem a questão dos transgênicos a um aspecto técnico, sem implicações políticas e de valores sociais e ambientais, de acordo com os comentários do grupo.

Além disto, observou-se que os biotecnólogos, apesar de ter sido a categoria com o maior número de consultas realizado, foi a mais refratária à participação desta pesquisa. Em seus comentários, tais atores consideraram que opiniões mais precaucionistas ou contrárias são manipuladas por ideologias sem teor científico. Apenas um especialista que atua exclusivamente na área de biossegurança apresentou argumentos opostos.

A respeito dos órgãos governamentais que devem participar das tomadas de decisão, a maioria das categorias foi favorável a uma maior coordenação entre diversas instituições abrangendo outras além da CTNBio e o CNBS.

No tocante à importância dos aspectos relevantes a serem considerados em estudos ambientais de PGMs, a maioria dos participantes os considerou como importantes. No entanto, a primeira categoria biotecnologia e/ou biossegurança - diferiu das demais, por apresentar uma menor avaliação quanto a necessidade de considerar outras alternativas tecnológicas, provavelmente em função da área de atuação dos participantes que, em sua maioria, os desenvolvem.

Particularmente no tocante aos instrumentos de estudos ambientais, sobressalta-se o desconhecimento dos participantes em geral sobre suas prerrogativas, como demonstrado pela boa avaliação do aspecto "consideração dos impactos cumulativos" para a Análise de Risco, a qual não possui tal atribuição, de acordo com a Normativa $\mathbf{n}^{\circ}$ 05/2008 da CTNBio.

No tocante ao entendimento sobre o modelo regulatório de PGMs adotado no Brasil, a maioria dos participantes, com exceção da primeira categoria - biotecnologia e/ou biossegurança -, mostrou insatisfação com todos os critérios levantados. Por meio dos comentários, nota-se uma desconfiança dos órgãos que o compõem, os quais parecem defender estritamente os interesses das multinacionais produ- 
toras de transgênicos. Daí provavelmente se deriva a não implementação do Sistema de Informações em Biossegurança (SIB), órgão presente na Lei de Biossegurança e que teria o papel de dispor todas as informações relacionadas a PGMs, tais como os processos, pleitos, análises de risco conduzidas pelas empresas proponentes, relatórios dos órgãos fiscalizadores, dentre outros, de forma sistematizada.

A falta de transparência, de participação social, monitoramento pós-comercial e legitimidade decorrem, segundo a opinião expressa pela maioria dos participantes, do interesse do governo em proteger o mercado para os produtos da bioindústria.

Apesar das críticas e da necessidade de se modificar o marco regulatório de PGMs no Brasil, considera-se que o espaço amostral deve ser ampliado por meio de novos estudos, que contemplem um maior número de participantes, além de outros questionamentos que sejam pertinentes ao assunto, para que se faça um panorama mais representativo e indicativo acerca das opiniões e visões de futuro dos diversos setores sociais sobre o modelo regulatório de PGMs no Brasil.

\section{AGRADECIMENTOS}

A CAPES (Coordenação de Aperfeiçoamento de Pessoal do Nível Superior), pelo apoio financeiro com a manutenção de bolsa de auxílio.

\section{REFERÊNCIAS}

ALSHUWAIKHAT, H. M. Strategic environmental assessment can help solve environmental impact assessment failures in developing countries. Environmental Impact Assessment Review, v. 25, p. 307-313, 2005. DOI: http://dx.doi.org/10.1016/j.eiar.2004.09.003

ALTIERI, M.; NICHOLLS, C. I. Agroecologia: Teoría e práctica para una agricultura sustentable. México: PNUMA, 2000. (Série Textos Básicos para la Formación Ambiental, 4). Disponível em http:www. agro.unc.edu.ar/ biblio/AGROECOLOGIA[1].pdf. Acesso: 20 de setembro de 2008.

BRASIL. Resolução CONAMA n ${ }^{\circ} 001$, de 23 de janeiro de 1986. Dispõe sobre critérios básicos e diretrizes gerais para o Relatório de Impacto Ambiental - RIMA. Diário Oficial [da] República Federativa do Brasil. Poder Executivo. Brasília, DF, 1986.

BRASIL. Resolução CONAMA $n^{\circ}$ 237, de 19 de dezembro de 1997. Dispõe sobre licenciamento ambiental; competência da União, Estados e Munícipios; listagem de atividades sujeitas ao licenciamento; Estudos Ambientais, Estudo de Impacto Ambiental e Relatório de Impacto Ambiental. Diário Oficial [da] República Federativa do Brasil. Poder Executivo. Brasília, DF, 1997.

BRASIL. Lei $n^{\circ} 11.105$, de 24 de março de 2005. Regulamenta os incisos II, IV e V do $\S 1$ o do art. 225 da Constituição Federal, estabelece normas de segurança e mecanismos de fiscalização de atividades que envolvam organismos geneticamente modificados - OGM e seus derivados, cria o Conselho Nacional de Biossegurança - CNBS, reestrutura a Comissão Técnica Nacional de Biossegurança - CTNBio, dispõe sobre a Política Nacional de Biossegurança - PNB, revoga a Lei no 8.974, de 5 de janeiro de 1995, e a Medida Provisória no 2.191-9, de 23 de agosto de 2001, e os arts. 5o, 6o, 7o, 8o, 9o, 10 e 16 da Lei no 10.814, de 15 de dezembro de 2003, e dá outras providências. Diário Oficial [da] República Federativa do Brasil. Poder Executivo. Brasília, DF, 2005.

BROOKES, G.; BARFOOT, P. GM crops: the global socioeconomic and environmental impact -the first nine years 1996-2004. Agbioforum, v. 8, p. 187-196, 2005.

CTNBIO. Resolução Normativa $n^{\circ}$ 5, de 12 de março de 2008. Dispõe sobre normas para liberação comercial de Organismos Geneticamente Modificados e seus derivados. Diário Oficial [da] República Federativa do Brasil. Poder Executivo. Brasília, DF, 2008.

DALE, P.J., CLARKE, B., FONTES, E.M.G. Impacto ambiental de variedades agrícolas geneticamente modificadas. In: PIRES, C.S.S.; FONTES, E.M.G.; SUJII, E.R. (Org.). Impacto Ecológico de Plantas Geneticamente Modificadas. Brasília: Embrapa, 2003, p.13-48. 
Modelo regulatório da liberação comercial de plantas geneticamente modificadas no Brasil: existe um consenso? Denise Gallo Pizella, Marcelo Pereira de Souza, Moacyr Lobo da Costa Jr.

ELY, A. Globalization and International Governance of Modern Biotechnology: Evaluating Environmental Risks of Bt Mayze in the US and EU: Lessons and Chalenges for Kenya. In: WORKSHOP ON GLOBALIZATION AND GOVERNANCE OF MODERN BIOTECHNOLOGY, WITH SPECIAL REFERENCE TO KENYA. Nairob, 2002. Anais... Nairob, 2002.

ISAAA. ISAAA Briefs 39-2008: Global Status of Commercialized Biotech/GM Crops: 2008: The First Thirteen Years, 1996 to 1998. 2009. Disponível em: http://www.isaaa.org. Acesso: 20 de setembro de 2011.

GUIVANT, J.S. Transgênicos e percepção pública da Ciência no Brasil. Ambiente \& Sociedade. V.09, n.1, p.81-103, 2006. DOI: http://dx.doi.org/10.1590/ S1414-753X2006000100005

HENRY, C. Cumulative long-term effects of genetically modified (GM) crops on human/animal health and the environment: risk assessment methodology. UK: Central Science Laboratory, 2006.

HINDMARSH, R. The need for effective assessment: sustainable development and the social impacts of biotechnology in the third world. Environ. Impact Assess. Rev., v. 10, p. 195-208, 1990. DOI: http://dx.doi.org/ 10.1016/0195-9255(90)90019-V

MACHADO, P.A.L. Direito Ambiental Brasileiro. São Paulo: Malheiros Editores Ltda, 21 ${ }^{\mathrm{a}}$. edição, 2005.

MILARÉ, E. Direito do Ambiente. São Paulo: Revista dos Tribunais, $4^{\mathrm{a}}$. edição, 2005.

MYSZCZUK, A.P.; GLITZ, F.; SANTOS, R.R. Políticas Públicas, tentativas de estabelecimento de Áreas Livres de OGMs no Brasil e a Liberação da Soja Roundup Ready. Revista Brasileira de Agroecologia, v. 4, n. 2, p. 13459-1361, 2009.

PARTIDÁRIO, M.R. Avaliação Ambiental Estratégica. Brasília: MMA/SQA, 2002.

PELAEZ, V. Biopoder e regulação da tecnologia: o caráter normativo da análise de risco dos OGMs. Am- biente \& Sociedade, v. 7, n. 2, p. 145-158, 2004. DOI: http://dx.doi.org/10.1590/S141-753X2004000200009

PESSÔA, L. T. G. Metodologia de Avaliação Ambiental Estratégica de Organismo Geneticamente Modificado na Agricultur. 2007. Tese (Doutorado em Ciências), Universidade Federal do Rio de Janeiro, Rio de Janeiro, 2007.

ROBIN, M.M. O Mundo Segundo a Monsanto: Da dioxina aos transgênicos, uma multinacional que quer o seu bem. São Paulo: Radical Livros, 2008.

SCHMIDT, M.; JOÃO, E.; ALBRECHT, E. Implementing Strategic Environmental Assessment. Heidelberg: Springer Berlin, 2005.

SILVEIRA, J.M.; BUAINAN, A.M. Aceitar riscos controlados para inovar e vencer desafios. In: VEIGA, J. E. (Org.). Transgênicos: sementes da discórdia. São Paulo: SENAC, 2007.

SMITH, J.M. Roleta Genética: Riscos documentados dos alimentos transgênicos sobre a saúde. São Paulo: João de Barro Editora, 2009.

SNOW, A.A.; ANDOW, D.A.; GEPTS, P.; HALLERMAN, E.M.; POWER, A.; TIEDJE, J.M.; WOLFENBARGER, L.L. Genetically Engineered Organisms and the Environment: current status and recommendations. Ecological Applications, v. 15, n. 2, p. 377-404, 2005. DOI: http://dx.doi.org/10.1890/04-0539

STIRLING, A. A precautionary approach to technological appraisal? A multicriteria mapping of genetic modification in UK agriculture. TA-Datenbank Nachrichten, v.3, n. 9, p. 39-51, 2000.

SUZUKI, J.B. OGMs: aspectos polêmicos e a nova lei de biossegurança. Jus Navigandi, ano 11, n. 997, 2006. Disponível em $<$ http://jus.uol.com.br/revista/ texto/8148>. Acesso: 24 de agosto de 2011.

THERIVEL, R.; WILSON, E.; THOMPSON, S.; HEANEY, D.; PRITCHARD, D. Strategic environmental assessment. London, UK: Publications Limited, 1994. VEIGA, J. E. Introdução. In: VEIGA, J.E. (Org.). 
Transgênicos: sementes da discórdia. São Paulo: SENAC, 2007.

WALES, C.; MYTHEN, G. Risky Discourses: The Politics of GM Foods. Environmental Politics, v. 11, n.2, p.121-144, 2002. DOI: http://dx.doi.org/ $10.1080 / 714000604$ 